\title{
A procedure to determine the water-binding capacity of meat trimmings for cooked sausage formulation
}

\section{Pouttu, Petri}

Elsevier

2004

Meat Science. 2004. 66(2): 329-334 .

http://hdl.handle.net/1975/577

http://dx.doi.org/10.1016/S0309-1740(03)00107-4

Downloaded from Helda, University of Helsinki institutional repository.

This is an electronic reprint of the original article.

This reprint may differ from the original in pagination and typographic detail.

Please cite the original version. 
WBC_MSci.doc; 15.11.06: 10:25

1 A procedure to determine the water-binding capacity of

2 meat trimmings for cooked sausage formulation

3

4 Petri Pouttu and Eero Puolanne*

5 Department of Food Technology/Meat Technology, University of Helsinki.

6 Viikki E, P.O. Box 27, 00014 Helsinki, Finland

7

8

9

10

11

12

13

a) Present Address: Taifun Ltd, Nuijamiestentie 5 B, 00400 Helsinki, Finland

\section{Abstract}

An attempt was made to determine the water-binding capacity of each individual trimming in a multicomponent system. Three types of experimental cooked sausages (finely chopped luncheon sausage, coarsely chopped sausage and ring sausage with potato starch) were made of five different meat trimmings: two pork trimmings and two beef trimmings, and one beef trimming used as a replacer. The water-binding was determined by the Tuominen-Honkavaara method by stepwise addition of water (basic formulation and four water additions) to the formulations and determining the firmness by a consistometer. The water-binding of each trimming was obtained by replacing the trimming by an additonal trimming. A total of 3 sausage types $x 5$ meat trimmings $x 5$ water levels giving 75 experimental batches of five $\mathrm{kg}$ each were made.

The average water-binding values of the same meat trimming combination in each sausage type were practically the same, and therefore the total averages for the same 
1 meat trimming combinations of each of the three sausage types were used for the

2 subsequent calculations. The determination of the water-binding values of the meat

3 trimmings were solved by forming five equations with four unknowns each, and then

4 solving the unknowns using Microsoft Excel's 'Solver' function. By this procedure it was

5 possible to determine the water-binding of individual meat trimmings in sausage systems.

6 This procedure can be used for the determination of the technological properties of meats

7 for linear programming.

8

9 Keywords: water-binding, cooked sausage, meat trimmings, linear programming. 
4 Cooked sausage is a multicomponent meat system, where the producer attempts to

5 maximize the organoleptic and other quality traits, typical to the product in question, at

6 minimal costs. Usually, the consistency (firmness) of the sausage is the critical

7 technological trait limiting any further increase of water and fat, at the cost of lean meat.

8 The water-binding (and fat-binding), and structural traits, respectively, are basically

9 based on the same microstructural factors, mainly protein-water interactions and gel

10 formation in myofibrils and connective proteins.

12 Traditionally, sausage formulations were designed by experts who, based on their

13 experience, were able to obtain the desired properties for the sausages. They were able to

14 plan simultaneously a product mixture for the factory in which the carcasses were used

15 totally without the accumulation of trimmings. Usually, the sausage formulations were

16 constant for long periods of times. When the factories became larger, more advanced

17 methods for large-scale production were needed. In the sixties, one-goal linear

18 programming, aiming at least cost formulation, was introduced to the meat industry. The

19 purpose was to optimize the usage of the carcass derived ingredients with a standard

20 quality with minimal costs and maximum profit (Snyder \& French, 1993; review Turkki

21 1994). The optimization was based on (i) the standardized compositions or (ii) the

22 known compositions of meat trimmings and (iii) their water-binding and (iv) fat-binding,

23 and on (v) the standard compositions of the final products. The restrictive equations are

24 derived to limit the water and fat additions based on the additive water-binding and fat- 

binding capacities of the ingredients. Then the program optimizes the formulation by

2 minimizing the ingredient costs.

4 Consequently, the basic foundation of this linearly additive system is that the composition

5 and the binding values of the ingredients should be constant in different types of sausage

6 formulations. The technological properties of meat trimmings can be estimated based on

7 their chemical composition, i.e. water, protein, and fat contents. As there is an

8 inhomogenity in the chemical composition and other technological properties of meat

9 trimmings, a consistency in the properties can only rarely be achieved. There are many

10 inaccuracies in the system. The water, protein and fat contents always differ in different

11 batches. Additionally, the $\mathrm{pH}$-temperature history, the relative proportion of connective

12 tissue and its properties, factors influencing the technological properties cause differences

13 in the final product. Puolanne and Ruusunen (1981) were able even to show that an

14 increase in the relative amount of collagen in meat trimmings may partly inhibit the

15 positive effects of myofibrillar proteins.

16

17 There are several methods that have been used to determine the water-binding capacity of

18 meat. The laboratory methods can clearly show the relative differences between the

19 trimmings, but they all have their restrictions on giving absolute binding values for the

20 trimmings to be used in industrial scale cooked sausages. Since Hansen (1960) published

21 the well-known emulsion hypothesis for finely-chopped cooked sausage mass, the

22 emulsifying capacity of meat trimmings has been used as a trait for the technological

23 capacity of a trimming. The emulsifying capacity was determined using $3 \% \mathrm{NaCl}$ in a

24 water:meat homogenate at a ratio of 150:40 (Carpenter \& Saffle, 1964) or higher to

25 extract the salt soluble proteins and then test the capacity of the extract to emulsify 
vegetable oil. This is unrealistic when compared to the circumstances in a

2 multicomponent cooked sausage, where the added water:lean meat ratio is less than 1 and

3 where fat is mostly solid. Carpenter and Saffle (1964) found that the amount of soluble

4 protein from the same sample of meat extract was linearly related to the amount of

5 emulsified oil. But when comparing the emulsifying capacity of extracts (g oil/ $100 \mathrm{mg}$

6 soluble protein) from different types of meat, great differences were seen.

8 There are a few laboratory or pilot scale methods published that include the cooking of

9 the batter (e.g. Hamm \& Grabowska, 1978; Puolanne \& Ruusunen, 1978; Tuominen \&

10 Honkavaara, 1982). By determining the water-binding (and in some cases the fat-

11 binding) in a one-trimming experimental sausage does not give a realistic value for a

12 multicomponent system, because the replacing of one trimming with another creates the

13 problem of there being two variables in one test.

15 It has not been shown that the properties of trimmings are really directly additive.

16 Puolanne and Ruusunen showed that the water-binding of an ingredient (different meat

17 trimmings (1983a), nonfat milk powder and potato flour (1983b)) is dependent of its

18 content in the formulation. The relative water-binding (kg bound water/ kg íngredient)

19 was higher in lower contents of an ingredient in the formulation. Puolanne and

20 Ruusunen (1980) and Puolanne and Turkki (1984) also showed that, especially at levels

21 lower than ten percent fat in the sausage, increasing fat content strongly increased the

22 water-binding. Consequently, there are interactions between the ingredients, a situation

23 that has not been widely studied. Finally, it is well-known that the salt content and

24 eventual use of added phosphate have much influence on the water-binding of (meat)

25 ingredients. 
2 It seems evident that the present practices do not give exact constant values for

3 optimization systems, normally computed using linear programming. Therefore, in

4 practical industrial circumstances, rather large safety margins for binding values are used.

5 Additionally, the formulation program usually contains preset ranges for most

6 ingredients. Consequently, this may mean that the programs are set to calculate for the

7 cheapest meat ingredients combination, not the water-binding values.

9 This study examines the water-binding capacity of a meat trimming in a multicomponent

10 sausage formulation by determining the effects of water additions on sausage firmness.

11 The goal is to find a method to obtain the additive water-binding value that, in constant

12 salt and phosphate contents, is not dependent on the effects of the other ingredients in

13 cooked sausage.

\section{Materials and methods}

17 The water-binding (i.e. the ability of an ingredient to contribute to the gel formation or

18 firmness, when water has been added) was determined by the method of Tuominen and

19 Honkavaara (1982). In a pilot plant, three types of cooked sausage were made, using two

20 beef trimmings and two pork trimmings plus one an additional trimming as the replacer

21 (Table 1). The cooked sausages were: luncheon type finely chopped sausage with 80\%

22 meat, ring sausage with 6\% potato flour (77\% meat) and coarsely chopped sausage (85\%

23 meat). Each sausage was made of four trimmings, each being $25 \%$ of the total meat. The

24 first sausage batch was made with the four experimental trimmings, and then another four

25 batches of sausages were made by replacing "one-by-one" the trimmings in each one with 


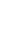

another trimming, called replacer (See Equations 1-5). Unfortunately, two different replacer trimmings (NEL or N3, Table 1) had to be used in this study to obtain the desired fat contents in the different sausage types. The basic formulation of each sausage type is given in Table 1 .

The batch size was $30 \mathrm{~kg}$. Batches were first chopped for about half of the total time. Then each batch was divided into five parts, and additional water (0, 3, 6, 9 and 12\% (luncheon-type and ring sausage) or 0, 2, 4, 6 and $8 \%$ (coarsely chopped sausage)) was added to the batches and then chopped to completion. 2.0\% low sodium salt mixture and 0.25\% phosphate (Carfosel 21, Europhos, France (E 450), sodium polyphosphate, 57\% $\mathrm{P}_{2} \mathrm{O}_{5}, \mathrm{pH}$ of the $1 \%$ solution 7.2 ) additions were increased to maintain a constant level in the final product. Batters were stuffed into $\varnothing 70 \mathrm{~mm}$ casing, smoked, cooked to $72{ }^{\circ} \mathrm{C}$ core temperature and cooled.

Firmness was determined 2-4 days after preparation. Cubes, $5 \times 5 \times 5 \mathrm{~cm}$, were cut from the sausages. The firmness of the cubes was measured with the Instron Universal Testing Machine TM-100 (Instron Ltd, High Wycombe, England) by compressing them $1 \mathrm{~cm}$ using a $\varnothing 55 \mathrm{~mm}$ piston. The temperatures of the cubes were $13-17^{\circ} \mathrm{C}$. Three cubes were measured from each sausage twice, and the means of the six values are given in kilogrammes. The means were plotted against additional water ( $\mathrm{kg}$ water $/ \mathrm{kg}$ meat in the formulation) using Microsoft Excel 97 program, and the line was determined using the 'Trendline' function that also gives the equation of the trendline and its R-square values $\left(R^{2}\right)$. Then, finally it was determined at what level of added water the trendline crosses the preset firmness value of $6 \mathrm{~kg}$. This value was used to express the water-binding of each meat trimming combination. 
2 A system of equations was derived as follows: The codes of trimmings (see Table 1) S2,

3 SP, NEL (the replacer in the ring sausage and the coarsely chopped sausage), N2, N3 (the

4 replacer in luncheon type sausage); A, B, C, D, E: the water-binding values of the

5 sausages (Table 2; $\underline{\mathrm{A}}$, respectively) (kg water/kg meat mixture in sausage mass)

6 determined by the Tuominen Honkavaara method, see above):

7

8

9

10

11

12

13

14

15

16

17

18

19

20

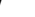

The water-binding values for each unknown (SP, etc.) were solved by Microsoft Excel 97 using the 'Solver' function resulting in the water-binding values of the individual trimmings.

The fat contents of the meat trimmings and finished sausages were determined by the Gerber method (DIN 10310).

\section{Results and discussion}

The fat contents of the meat trimmings are given in Table 1. Because the trimmings were obtained from industrial cutting, there were rather large differences between the 
1 individual tests. The targeted fat contents of the finished sausages were calculated on the

2 basis of the fat contents of the trimmings used in each case. The analysed fat contents of

3 the sausages of different trimming combinations within the sausage series were (results

4 not given), however, variable indicating defects in the homogenization of meat trimmings

5 and their analysis. This did not, however, affect the results seriously, as seen below.

7 The results of the firmness determinations of the sausages and their trendlines are given

8 in Figures 1-3 and the respective water-binding values on the 6-kg firmness level in Table

92 2; . Because the recipes for luncheon-type and ring sausage resembled each other, the

10 average difference of water-binding capacities of these two sausages can be approximated

11 to derive that for potato flour. The average difference in water-binding, was $60 \mathrm{~g} / \mathrm{kg}$

12 (expressed as g water bound $/ \mathrm{kg}$ meat). This indicates a potato flour content of $60 \mathrm{~g} / \mathrm{kg}$

$131000 \mathrm{~g}$ bound water/kg potato flour. This is, however, a smaller value than that used in

14 the industry (ca. 2500g bound water/kg potato flour; personal communication). When

15 large quantities of water are used, potato flour is able to form a gel thus increasing the

16 firmness, but in this case the high meat content seemed to have been principally

17 responsible for the firmness, and potato flour did not have its full effect. Because the

18 results for all sausage types were approximately at the same level (after deduction of the

19 effect of potato flour), it was decided to use the mean value of the results of all three

20 sausage types, after excluding the effect of potato flour on the water-binding, from the

21 results of the ring sausages.

22

23 A system of five equations (Equations 1-5 in Table 2; $\underline{\mathrm{A}}$ ) was derived to solve the five

24 unknowns (i.e. the water-binding of each individual meat trimming (Table 2; $\underline{B}$ ).

25 Because each meat trimming is $1 / 4$ of the total meat content, the results obtained from the 
Solver-solution were multiplied by a factor 4 to express the results in $\mathrm{kg}$ added water $/ \mathrm{kg}$

2 meat trimming.

3

4 The water-binding values for each trimming are in accordance with industrial experience.

5 Therefore, it seemed that the procedure gives a realistic approach to the problem.

7 The linear regression coefficients of firmness-water additions -curves were usually very

8 high ( $\mathrm{R}^{2}$ over 0.90 in all cases except one of about 0.80 , Figures $\left.1-3\right)$. Theoretically, the

9 trendline relative to firmness/added water should be hyperbolic, but these low changes in

10 contents made the relationship close to linear. A hyperbolic relationship is seen for the

11 effects of non-meat ingredients, when the content of the ingredient varies more than it

12 does here (Puolanne \& Ruusunen, 1983; Puolanne, review 1991).

14 The following limitations should be noted. Normally linear programming programs use

15 the capacity to bind added water and the total water as well (the moisture in the

16 ingredients plus the added water). The programs limit the amount of the added water so

17 that the sum of water-binding capacities of the ingredients is as large as or higher than the

18 total amount of water in the formulation. The results of our procedure is given as water-

19 binding capacity, but actually it gives values for meat/water interactions relative to

20 firmness. Additionally, the procedure does not give values for fat-binding. The values

21 are also affected by the salt content and the eventual use of phosphates, which causes

22 variation in the absolute water-binding values between the various sausages/formulations.

23 Consequently, the water-binding values are due to only the salt content and phosphate

24 content that have been used in the determinations. The same problem applies also to all

25 other methods. If this procedure was applied in an industrial production optimization 

using linear programming, each meat trimming would have to be tested several times to

2 determine any batch to batch variation. This means that the water-binding values of the 3 trimmings must be tested in each factory.

4

5 Puolanne (review, 1999) presented a hypothesis that the water-binding capacity of an

6 ingredient is related to the content of the ingredient in the formula and ingredient to

7 ingredient interactions. This has been shown to be particularly true with non-meat

8 ingredients (Puolanne \& Ruusunen, 1983b). In this study the meat contents of the

9 formulas were $77-85 \%$, too small a range to show marked differences due to the meat

10 content. There was, however, a tendency towards a lower water-binding capacity values

11 (i.e. relative effect on firmness/weight unit of meat ingredient) in sausages of higher meat

12 content. Therefore, the hypothesis was not rejected but will be further studied later. If

13 the hypothesis still holds it would further increase the inaccuracy of linear programming

14 and require safety margins for structure and organoleptic traits. It must be noted that

15 water-binding should be regarded as a linearly additive measure (within a certain range).

16 Fat binding is also strongly based on the ability of the ingredients to form a gel that holds

17 the water, and to lesser extent on the ability of the ingredients to bind fat by some

18 mechanism, e.g. emulsification. Theoretically, the gel strength is exponentially related to

19 the content of the ingredient responsible for gelling. Consequently, the theoretical

20 foundations of linear programming include many inaccuracies which require several

21 approximations.

22 
1 The results showed that a procedure, based on the effects of increased water additions on

2 firmness and on a replacement of the trimmings one-by-one by a same trimming, and on

3 a mathematical treatment, can be used to determine the water-binding capacity (effect on

4 firmness) of an individual meat trimming in a multicomponent system.

5

6 Acknowledgements

7

8 This study was financially supported by Fa. Pouttu Ltd, Kannus, Finland. The languade

9 was kindly checked by Mr. Donald Smart at Language Centre, University of Helsinki.

10

11 References

12

13 Carpenter, J Saffle, R. 1964. A simple method of estimating the emulsifying capacity of

$14 \quad$ various sausage meats. J. Food Science 26, 774-781.

15 Grabowska, J. \& Hamm, R. 1978. Proteinlöslichkeit und Wasserbindung unter den in

16 Brühwurstbräten gegebenen Bedingungen. III Mitteilung: Einfluss des Fleisches:

17 Wasser-Verhältnisse und der Zerkleinerungsbedingungen. Fleischwirtschaft 59, 1529-

$18 \quad 1534$.

19 Hansen, L. 1960. Emulsion formation in finely comminuted sausages. Food Technology

$20 \quad 14,565-569$.

21 Puolanne, E. 1999. Cooked meat products. Review. In Proceedings 45th International

22 Congress of Meat Science and Technology (pp. 116-120), Yokohama, Japan.

23 Puolanne, E. \& Ruusunen, M. 1978. Verfahren zur Untersuchung der Eigenschaften von

24 Brühwurstbrät. Fleischwirtschaft 58, 1543-1544. 
1 Puolanne, E. \& Ruusunen, M. 1980. Über das Wasserbindungsvermögen der Brühwurst-

2 Rohstoffe. Fleischwirtschaft 60, 1041-1043.

3 Puolanne, E. \& Ruusunen, M. 1981. The properties of connective tissue membrane and

$4 \quad$ pig skin as raw materials for cooked sausage. Meat Science 5, 371-382.

5 Puolanne, E. \& Ruusunen, M. 1983a. Einfluss von Salzzusatzes auf das

$6 \quad$ Wasserbindungsvermögen des Fleisches in Brühwurst verschiedener Rezepturen.

$7 \quad$ Fleischwirtschaft 63, 238-239.

8 Puolanne, E. \& Ruusunen, M. 1983b. Die Wirkung von Kartoffelmehl und Milchpulver

$9 \quad$ auf das Wasserbindungsvermögen und die Konsistenz bei Brühwurst.

$10 \quad$ Fleischwirtschaft 63, 631-633.

11 Puolanne, E. \& Turkki, P. 1984. The effect of the level of hot boned pork fat on water-

12 binding capacity and fat retention in cooked sausage. In Proceedings 30th European

13 Meeting of Meat Research Workers, Bristol, UK, 7.28, 373-374.

14 Snyder, J. \& French, C. 1963. Disassembly-assembly models for meat packing

15 management. Purdue University Agricultural Experiment Station Bulletin No 764.

16 Lafyette, Indiana.

17 Tuominen, R. \& Honkavaara, M. 1982. Effect of electrically stimulated meat on

18 processing properties of cooked sausage. In Proceedings 28th European Meeting of

$19 \quad$ Meat Research Workers, Madrid, Spain: 4.18.

20 Turkki, P. 1994. Production control of integrated meat plants. (PhD. thesis). Acta

21 Polytechnica Scandinavica, Mathematics and Computing in Engineering, Series No

$22 \quad 68.218 \mathrm{p}$. 
2 Table 1. Basic sausage formulations

\begin{tabular}{|c|c|c|c|}
\hline Ingredient & Luncheon type & Coarsely chopped & Ring sausage \\
\hline S2 (Pork, 35\% fat) & $6.00 \mathrm{~kg}$ & $5.95 \mathrm{~kg}$ & $5.78 \mathrm{~kg}$ \\
\hline SP (Pork, 19\% fat) ${ }^{1}$ & $6.00 \mathrm{~kg}$ & $5.95 \mathrm{~kg}$ & $5.78 \mathrm{~kg}$ \\
\hline NEL (Beef, 15\% fat) & $6.00 \mathrm{~kg}$ & Replacer & Replacer \\
\hline N2 (Beef, 18\% fat) & $6.00 \mathrm{~kg}$ & $5.95 \mathrm{~kg}$ & $5.78 \mathrm{~kg}$ \\
\hline N3 (Beef, 27\% fat) & Replacer & $5.95 \mathrm{~kg}$ & $5.78 \mathrm{~kg}$ \\
\hline Water & $5.27 \mathrm{~kg}$ & $3.52 \mathrm{~kg}$ & $4.73 \mathrm{~kg}$ \\
\hline Potato flour & & & $1.80 \mathrm{~kg}$ \\
\hline Salt $\operatorname{mix}^{2}$ & $0.60 \mathrm{~kg}$ & $0.56 \mathrm{~kg}$ & $0.60 \mathrm{~kg}$ \\
\hline Phosphate $^{3}$ & $75 \mathrm{~g}$ & $70 \mathrm{~g}$ & $75 \mathrm{~g}$ \\
\hline Nitrite & $120 \mathrm{mg} / \mathrm{kg}$ & $120 \mathrm{mg} / \mathrm{kg}$ & $120 \mathrm{mg} / \mathrm{kg}$ \\
\hline Ascorbic acid & $600 \mathrm{mg} / \mathrm{kg}$ & $600 \mathrm{mg} / \mathrm{kg}$ & $600 \mathrm{mg} / \mathrm{kg}$ \\
\hline Total & $30.00 \mathrm{~kg}$ & $28.00 \mathrm{~kg}$ & $30.00 \mathrm{~kg}$ \\
\hline \multicolumn{4}{|c|}{${ }^{1}$ Mechanically deboned pork } \\
\hline \multicolumn{4}{|c|}{${ }^{2}$ Salt mixture containing 57\% NaCl, 28\% KCl, 12\% $\mathrm{MgSO}_{4}\left(\mathrm{Pan}\right.$ Salt ${ }^{\circledR}$ ) } \\
\hline
\end{tabular}


2 Table 2. The system of equations and the water-binding values of the trimmings (Codes

3 of the trimmings, see Table 1$)$.

4

A System of equations

1) $\mathrm{S} 2+\mathrm{SP}+\mathrm{NEL}+\mathrm{N} 2=0.366[\mathrm{~kg}$ water/ kg meat $]$

2) $\mathrm{N} 3+\mathrm{SP}+\mathrm{NEL}+\mathrm{N} 2=0.395 "$

8

3) $\mathrm{S} 2+\mathrm{N} 3+\mathrm{NEL}+\mathrm{N} 2=0.460$ "

4) $\mathrm{S} 2+\mathrm{SP}+\mathrm{N} 3+\mathrm{N} 2=0.357 \quad$ "

10

5) $\mathrm{S} 2+\mathrm{SP}+\mathrm{NEL}+\mathrm{N} 3=0.343 \quad "$

11

B Excel Solver solutions of the water-binding values of the trimmings: 
2 Figure 1. Added water - firmness diagram of the luncheon type sausage

3 Figure 2. Added water - firmness diagram of the coarsely chopped sausage

4 Figure 3. Added water - firmness diagram of the ring sausage 


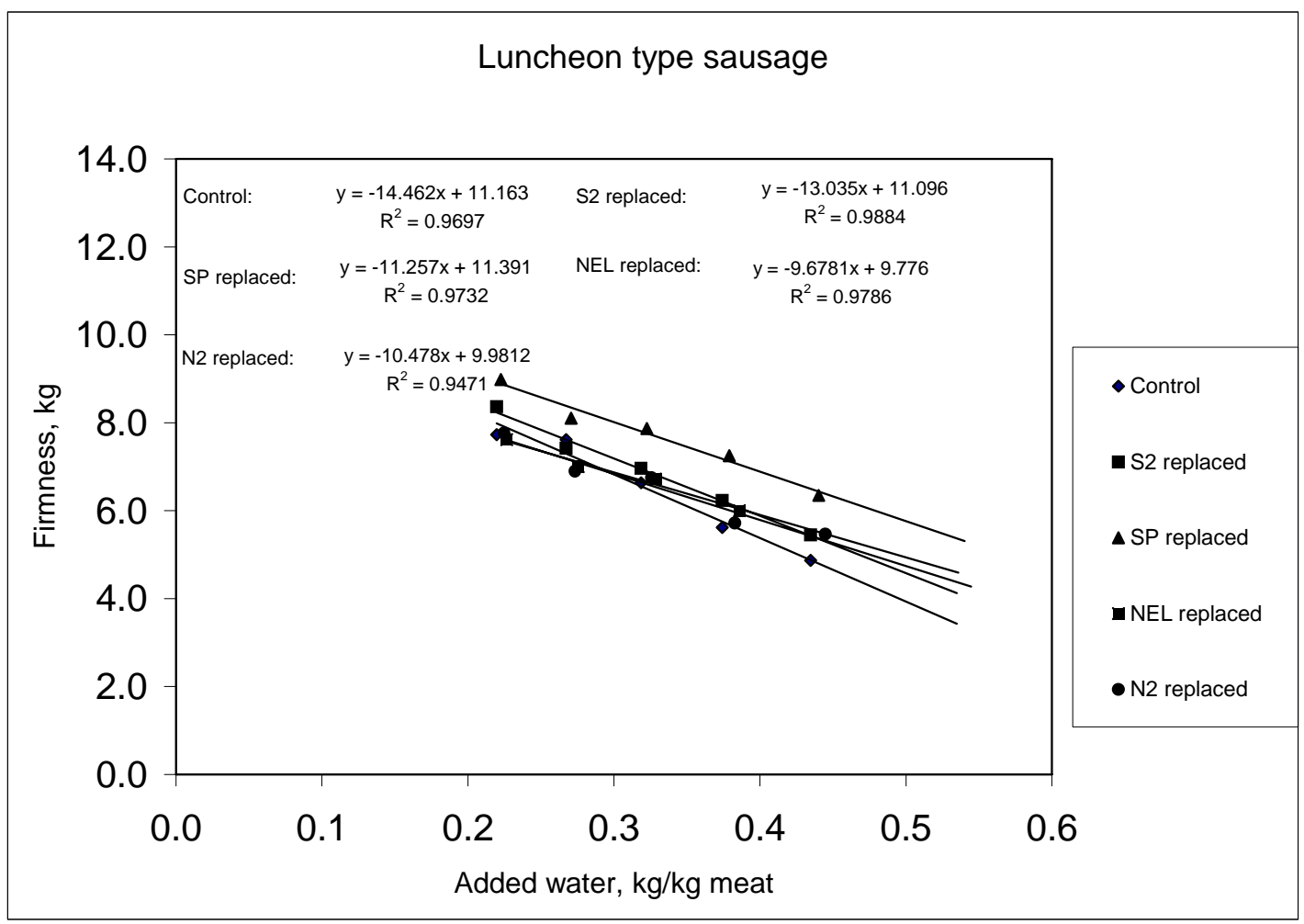

4 (Codes of the trimmings, see Table 1). 
Figure 2.

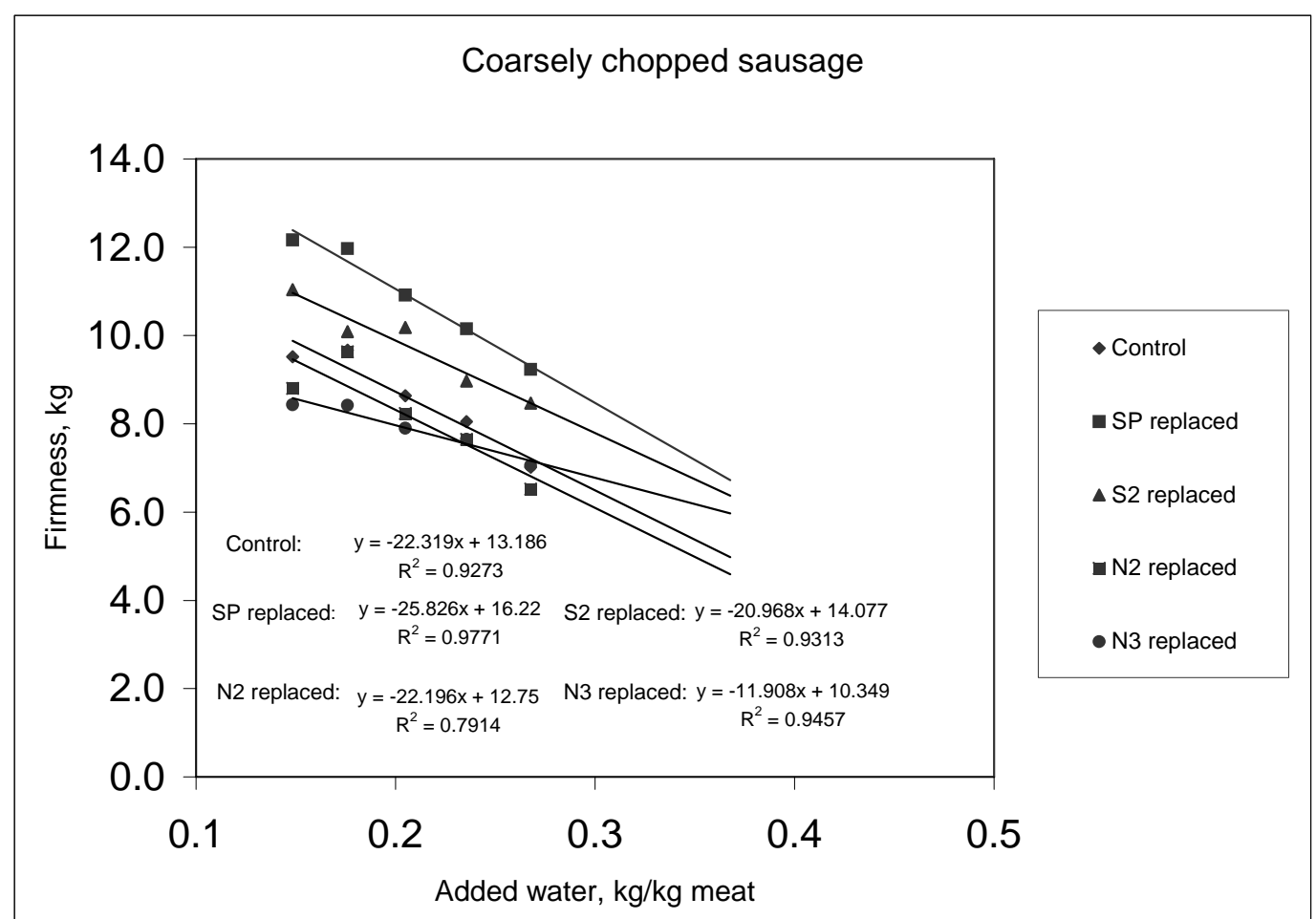

2 (Codes of the trimmings, see Table 1).

3

4

5

6 
Figure 3.

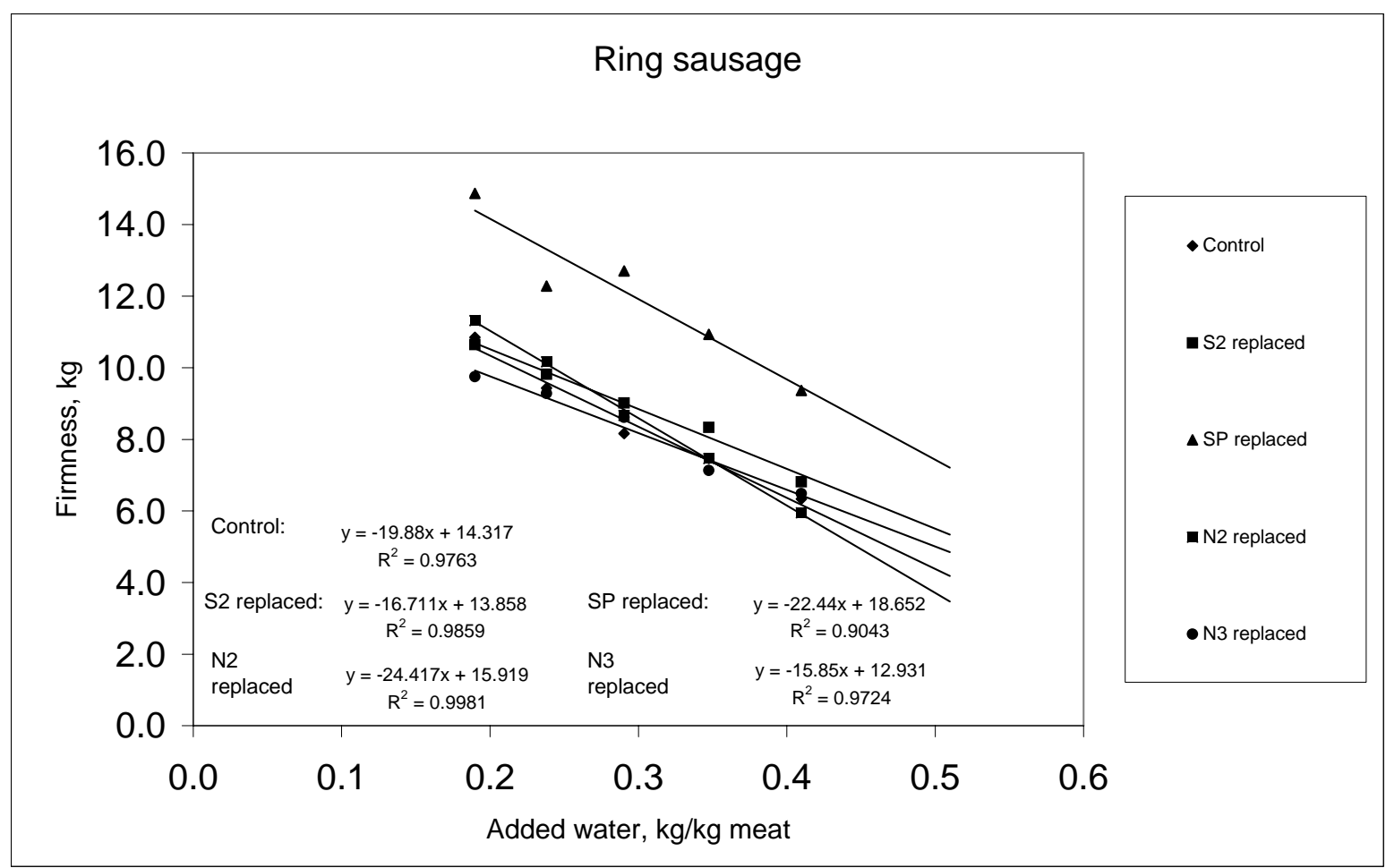

2 (Codes of the trimmings, see Table 1). 